Tropical Journal of Pharmaceutical Research July 2018; 17 (7): 1263-1269

ISSN: $1596-5996$ (print); 1596-9827 (electronic)

(c) Pharmacotherapy Group, Faculty of Pharmacy, University of Benin, Benin City, 300001 Nigeria.

\title{
Characteristics and anticancer properties of Sunitinib malate-loaded poly-lactic-co-glycolic acid nanoparticles against human colon cancer HT-29 cells lines
}

\author{
Abdullah S Alshetaili ${ }^{1 *}$, Md Khalid Anwer ${ }^{1}$, Saad M Alshahrani ${ }^{1}$, Ahmed \\ Alalaiwe ${ }^{1}$, Bader B Alsulays ${ }^{1}$, Mohammad Javed Ansari ${ }^{1}$, Faisal Imam ${ }^{2}$, Sultan \\ Alshehri $^{3}$ \\ ${ }^{1}$ Pharmaceutics Department, College of Pharmacy, Prince Sattam Bin Abdulaziz University, Alkharj, ${ }^{2}$ Department of \\ Pharmacology and Toxicology, ${ }^{3}$ Department of Pharmaceutics, College of Pharmacy, King Saud University, PO Box 2457, \\ Riyadh 11451, Saudi Arabia
}

*For correspondence: Email: a.alshetaili@psau.edu.sa; Tel: +966-566556617

Sent for review: 27 October 2017

Revised accepted: 9 June 2018

\begin{abstract}
Purpose: To develop poly-lactic-co-glycolic acid (PLGA) -based nanoparticles (NPS) for the delivery of sunitinib malate (STM) to colon cancer cells.

Methods: Three different formulations (F1 - F3) were developed by nano-precipitation technique using various concentrations of PLGA. The NPs were evaluated for particle size, polydispersity index, zeta potential, drug entrapment, and drug loading, using differential scanning calorimetry (DSC), Fouriertransform infrared spectroscopy (FTIR), x-ray diffraction (XRD), and scanning electron microscopy (SEM). Furthermore, in vitro drug release and anticancer studies were carried out on the formulations. Results: Among the three NPS, optimized NP (F3) of STM was chosen for in vitro anti-cancer study against $\mathrm{H}-29$ human colon cancer cells lines based on its particle size (132.9 nm), PDI (0.115), zeta potential (-38.12 $\mathrm{mV}$ ), entrapment efficiency (52.42\%), drug loading (5.24\%), and drug release (91.26 $\%$ in 48 h). A significant anti-cancer activity of the optimized NPs was observed, relative to free STM. Conclusion: These findings suggest that STM-loaded NPS possess significant anti-cancer activity against human colon cancer HT-29 cells lines.
\end{abstract}

Keywords: Sunitinib malate, Poly-lactic-co-glycolic acid, Nanoparticles, Colon cancer

\begin{abstract}
This is an Open Access article that uses a funding model which does not charge readers or their institutions for access and distributed under the terms of the Creative Commons Attribution License (http://creativecommons.org/licenses/by/4.0) and the Budapest Open Access Initiative (http://www.budapestopenaccessinitiative.org/read), which permit unrestricted use, distribution, and reproduction in any medium, provided the original work is properly credited.

Tropical Journal of Pharmaceutical Research is indexed by Science Citation Index (SciSearch), Scopus, International Pharmaceutical Abstract, Chemical Abstracts, Embase, Index Copernicus, EBSCO, African Index Medicus, JournalSeek, Journal Citation Reports/Science Edition, Directory of Open Access Journals (DOAJ), African Journal Online, Bioline International, Open-J-Gate and Pharmacy Abstracts
\end{abstract}

\section{INTRODUCTION}

Colorectal cancer (CRC) is the second main cause of malignancy-related death in the U.S. and in developing nations $[1,2]$. Substantial interest has been shown in medicinal agents that target oncogenic kinases, whose utilization may improve therapy and enhance the survival of CRC patients $[3,4]$.

Sunitinib malate (STM) is an orally-active compound approved by United States Food and Drug Administration (USFDA) as therapy for renal cell carcinoma and GIT stromal tumors. It 
has also been used for the treatment of some other malignancies, including colon cancer, breast cancer, neuro-endocrine cancer, and lung cancer in preclinical and clinical presentations [5-7]. It is a novel, multi-targeted receptor and tyrosine kinase inhibitor that impedes signaling through platelet-derived growth factor receptors (PDGFRs), vascular endothelial growth factor receptors (VEGFRs), and stem cell factor receptor (KIT) [8-11].

Thus, it would be beneficial to develop formulations that could deliver STM in a controlled manner for extended periods of time. However, this is difficult due to its poor watersolubility which limits its release, leading to instability. A successful attempt aimed at enhancing the solubility, dissolution, safety, and efficacy of the sunitinib malate through polymeric NP formations directly will improve the oral bioavailability of the drug, which, in turn, will reduce dosage and frequency. Poly-lactic-coglycolic acid (PLGA) is a biocompatible and biodegradable polymer frequently used in drug development due to its high solubility, encapsulation efficiency, controlled release, and low toxicity $[12,13]$.

Few studies have reported on polymeric NP formulations of STM [14,15]. Moreover, due to their small particle sizes, these polymeric systems have been found to be excellent carriers that enhance the solubility and bioavailability of various drugs with poor aqueous solubilities. In the present study, STM-loaded PLGA NPs were successfully developed. From preliminary characterization, the optimized STM-loaded PLGA NP with desirable properties was further evaluated for its in vitro anticancer activity.

\section{EXPERIMENTAL}

\section{Materials}

Sunitinib malate, PLGA (72: 25), and surfactant (pluronic acid F127) were procured from Sigma Aldrich (St. Louis, MO). Human colon cancer HT29 cell lines were procured from American Type Cell Culture (ATCC). Dialysis bags were purchased from Spectrum Medical Industries (Mumbai, India). Ultrapure water was obtained from Milli $Q$ water purifier unit from Pharmacy College.

\section{Preparation of STM-loaded PLGA nano- particles}

The NPs were prepared through the nanoprecipitation technique [12]. The STM was found to be insoluble in organic solvents such as dichloromethane, acetone, ethyl alcohol, and ethyl acetate, but it was readily soluble in DMSO. Different amounts of PLGA were dissolved in 9 $\mathrm{mL}$ of acetone, and $\mathrm{I} \mathrm{mL}$ of drug previously solubilized in DMSO was added to the solution of PLGA. The polymeric solution formed was further added to $10 \mathrm{ml}$ of aqueous surfactant solution (pluronic acid $F$ 127) at the rate of $0.3 \mathrm{ml} / \mathrm{min}$. Acetone was evaporated on a magnetic stirrer for $24 \mathrm{~h}$ at $45^{\circ} \mathrm{C}$, and the STM-entrapped PLGANPs were segregated from the bulk aqueousphase by centrifugation at $16,000 \mathrm{rpm}$ for $15 \mathrm{~min}$. The PLGA-NPs were thereafter washed thrice with distilled water and freeze-dried. The formulae of the prepared PLGA-NPs are shown in Table.1. Three different concentrations of PLGA polymer and pluronic acid F-127 were used in order to get higher entrapment efficiency, suitable particle size and drug release.

Table 1: Proportions of PLGA and pluronic acid used for PLGA-NPs preparation

\begin{tabular}{lccc}
\hline Formulation & $\begin{array}{c}\text { PLGA } \\
(\mathbf{m g})\end{array}$ & $\begin{array}{c}\text { Pluronic } \\
\text { acid F-127 } \\
(\mathbf{m g})\end{array}$ & $\begin{array}{c}\text { Acetone } \\
(\mathbf{m L})\end{array}$ \\
\hline F1 & 50 & 50 & 10 \\
F2 & 100 & 50 & 10 \\
F3 & 150 & 50 & 10 \\
\hline
\end{tabular}

\section{Particle characterization}

Malvern particle size analyzer (Holtsville, NY) was used to measure the particle size and PDI of the synthesized STM PLGA-NPs (F1 - F3) [16]. The NP dispersion was appropriately diluted (1:200), and sonicated for $10 \mathrm{~min}$ in order to get a clear dispersion. Then, $3 \mathrm{~mL}$ of the dispersion was analyzed in plastic cuvettes. Average size and PDI of each PLGA-NPs were measured in triplicate. The ZP values of the STM PLGA NPs (F1 - F3) were measured using Malvern Zetasizer.

\section{Evaluation of drug loading and entrapment efficiency}

The NPs were dissolved in organic solvent, lightly shaken, and sonicated for $6 \mathrm{~min}$. Then, methanol was used to precipitate the polymer that was present in the NPS. The sample was filtered, and the quantity of the drug present in the filtrate was measured with HPLC [8]. Drug loading (DL) was measured as the ratio of drug content of NPs to the total weight of the NPs. The entrapment efficiency (EE) was calculated as the proportion of entrapped drug in the NPs to the initial amount of drug that was added to the NPs. The experiments were carried out in triplicates. Entrapment efficiency and drug 
loading were determined as in Eqs 1 and 2, respectively.

$E E(\%)=\{(A-B) / A\} 100$

where $A=$ initial amount of drug added to the NPs, and $B=$ free, unentrapped drug.

$D L(\%)=(D E / T W) 100$

where $D E=$ entrapped drug, and $T W=$ total weight of the NPs

\section{In vitro drug release studies}

In vitro drug release of the developed NPs (F1F3) was studied by placing an amount of NPs (equal to $5 \mathrm{mg}$ of STM) in a treated dialysis bag in $50 \mathrm{~mL}$ of phosphate buffer, $\mathrm{pH}$ 6.8. The set up was shaken on a biological-shaker (LabTech, Korea) at $100 \mathrm{rpm}$ and $37 \pm 0.5^{\circ} \mathrm{C}$. At $0,0.5,1$, $2,3,4,5,6,7,8,9,10,11,12$, and $24 \mathrm{~h}, 1-\mathrm{mL}$ aliquots were withdrawn, diluted suitably with fresh buffer solution, and analyzed for the drug content using HPLC method [8]. The release of the drug from the optimized NPs was compared with drug release from pure STM. Based on the outcome, a formulation was selected for the cytotoxicity study.

\section{Differential scanning calorimetry (DSC)}

The thermal behavior of the NPs was analyzed by DSC (SCINCO, Italy). The three NP samples (F1 - F3) were each sealed in an aluminum pan and heated at a rate of $10^{\circ} \mathrm{C} / \mathrm{min}$ from 50 to 250 ${ }^{\circ} \mathrm{C}$ in the presence of nitrogen gas $(20 \mathrm{~mL} / \mathrm{min})$.

\section{Fourier-transform infrared spectroscopy (FTIR)}

FTIR spectral analysis was performed using an ALPHA-FTIR Spectrometer (OPTIK, USA). The samples of NPs (F1 - F3) were diluted with dry crystalline potassium bromide $(\mathrm{KBr})$, and transparent pellets were prepared by pressure application. Scanning was done for each sample in the wave number range of 4000 to $400 \mathrm{~cm}^{-1}$.

\section{X-ray diffraction (XRD) studies}

The XRD pattern of free STM and their NPS (F1 - F3) were scanned in Altima-IV X-ray diffractometer (Regaco, Japan). Each spectrum was scanned at a rate of $4 \% \mathrm{~min}$.

\section{Assessment of morphology of optimized NPs}

The morphology and the size of the optimized NPs (F3) were determined through SEM. In this process, the sample was put on copper grids with films after suitable dilution (1:5) and staining with $2 \% \mathrm{w} / \mathrm{v}$ phosphotungstic acid for $0.5 \mathrm{~min}$.

\section{In vitro anti-cancer studies}

The anti-cancer property of the best NPs (F3) was evaluated using MTT assay against HT-29 colon cancer cell lines. The percentage of cytotoxicity was measured by treating the cell lines with various concentrations of STM (2-20 $\mu \mathrm{M})$ from F3, NPs, and free STM. An optimized F3 without STM was used as a control formulation. The HT-29 cells were incubated under appropriate conditions as reported in the literature $[17,18]$, and $10 \mu \mathrm{L}$ of the MTT-reagent was put into each well. The concentration of formazan produced was measured with ELISAreader at $450 \mathrm{~nm}$.

\section{RESULTS}

\section{Particle characteristics}

The results of particle characterization of STMloaded PLGA-NPs are given in Table 2. The sizes of the three different STM-loaded PLGANPs (F1-F3) varied from $132.9 \pm 2.43$ to $250.1 \pm$ $6.72 \mathrm{~nm}$. The effect of concentration of surfactant (pluronic acid F-127) on particle size was not evaluated in this study. However, the influence of the polymer concentration on the size of the STM-loaded PLGA-NPs was evaluated. The smallest size of NPs was seen in F3 (132.9 \pm $2.43 \mathrm{~nm})$, while the largest size $(250.1 \pm 6.72$ $\mathrm{nm}$ ) was obtained in $\mathrm{F} 1$.

The PDI values of the NPs (F1-F3) ranged from 0.1 to 0.3 , indicating uniform distribution of particles. The F3 formula had the least PDI value (0.115 \pm 0.043$)$, confirming excellent uniformity of particles. However, the highest PDI was obtained in F1 $(0.282 \pm 0.021)$. The ZP values of the three developed STM-loaded PLGA-NPS (F1-F3) ranged from $-32.63 \pm 1.54$ to $-40.23 \pm$ $2.61 \mathrm{mV}$. These values of ZP which were higher than $\pm 30 \mathrm{mV}$ confirmed that all the NPs were stable (Figure 2).

\section{Entrapment efficiency and drug loading}

The degree of entrapment of STM was influenced by the amount of PLGA polymer used in the formulation. Loading efficiency of STM in F1-F3, ranging from 2.41-5.24\% were observed at different concentrations of PLGA as shown in Table 2. 
Table 2: Physicochemical characteristics of the STM NPS

\begin{tabular}{lccccc}
\hline Code & Size $(\mathbf{n m})$ & PDI & Zeta potential $(\mathbf{m V})$ & \% EE & $\%$ DL \\
\hline F1 & $287.9 \pm 4.27$ & $0.282 \pm 0.021$ & $-40.23 \pm 2.61$ & $48.24 \pm 1.60$ & $2.41 \pm 0.22$ \\
F2 & $250.1 \pm 6.72$ & $0.156 \pm 0.062$ & $-32.63 \pm 1.54$ & $43.06 \pm 2.52$ & $2.87 \pm 0.38$ \\
F3 & $132.9 \pm 2.43$ & $0.115 \pm 0.043$ & $-38.12 \pm 2.42$ & $52.42 \pm 1.31$ & $5.24 \pm 0.56$ \\
\hline
\end{tabular}

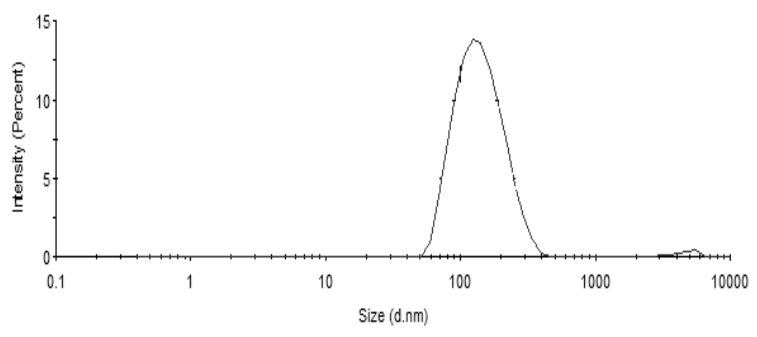

Figure 1: Mean size distribution of STM-loaded PLGA NPs (F3)

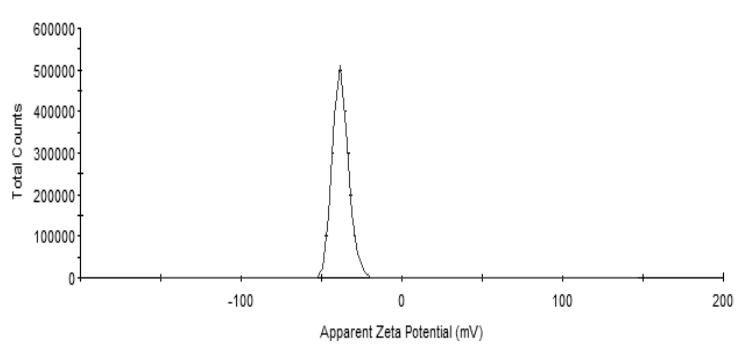

Figure 2: Zeta potential of STM-loaded PLGA NPS (F3)

\section{In vitro drug release}

The cumulative release of STM from NPs (F1F3) was markedly retarded/sustained after $48 \mathrm{~h}$, and about 69,76 , and $91 \%$ of the STM were released in the buffer media from F1, F2, and F3, respectively. The release pattern of the STM in all three NPs (F1-F3) confirmed that the F3 NPs were optimized (Figure 3).

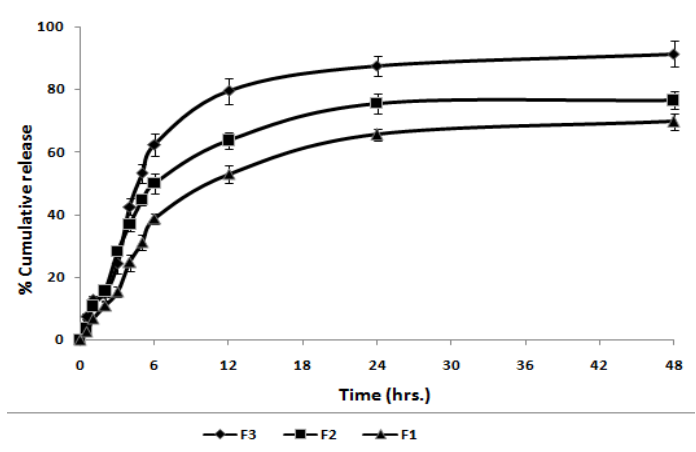

Figure 3: In vitro release of the nanoparticles (F1 F3)

\section{Thermal properties}

Thermal behaviors of the STM and STM-loaded PLGA-NPs (F1 - F3) were scanned from 50 to $250 \stackrel{\circ}{\circ}$ as shown in Figure 4. A sharp endothermic peak corresponding to $208^{\circ} \mathrm{C}$ was obtained in the case of free STM, which was found to be approximately the same with those done by the capillary method [19]. However, STM endothermic peaks disappeared in all NPs confirming its complete entrapment inside the PLGA polymeric matrix.

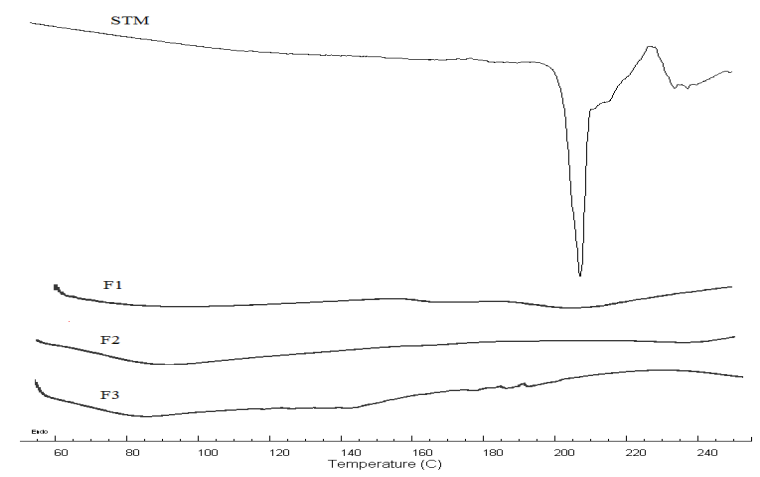

Figure 4: DSC thermograms of STM and drug-loaded PLGA-NPs (F1-F3)

\section{Fourier-transform infrared spectroscopy (FTIR)}

Many sharp peaks could be seen in the STMloaded PLGA-NPs with diminished intensity, corresponding to the peaks of pure STM in the fingerprint region $\left(400-1600 \mathrm{~cm}^{-1}\right)$. The reduction in peak intensity could be due to the loading of STM inside PLGA polymer [20].

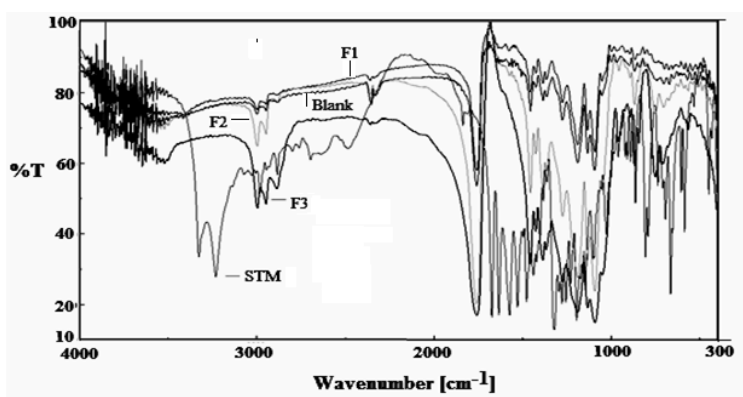

Figure 5: FTIR spectra of developed nanoparticles (F1-F3)

\section{X-ray diffraction (XRD) pattern}

The XRD pattern of pure STM and STM-loaded PLGA NPs (F1 - F3) are shown in Figure 6. Various sharp peaks could be observed in the XRD pattern of pure STM. However, these sharp peaks were diminished or absent in intensity in 
the STM-loaded PLGA NPS (F1 - F3). This revealed that the STM were successfully loaded into the polymer.
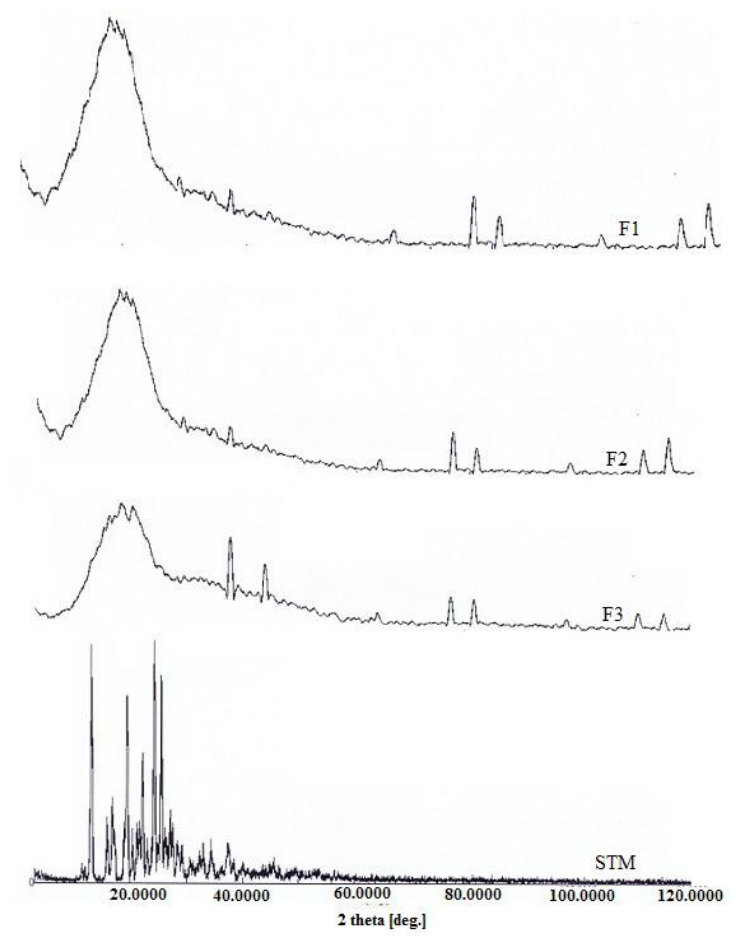

Figure 6: X-ray diffractograms of the nanoparticles (F1-F3)

\section{Morphology}

The images generated through SEM of optimized STM-loaded PLGA NPs (F3) are shown in Figure 7. It can be seen from the image that the developed NPs were small and spherical in shape. The particle size in the SEM image was approximately the same as the result obtained from particle size analyzer.

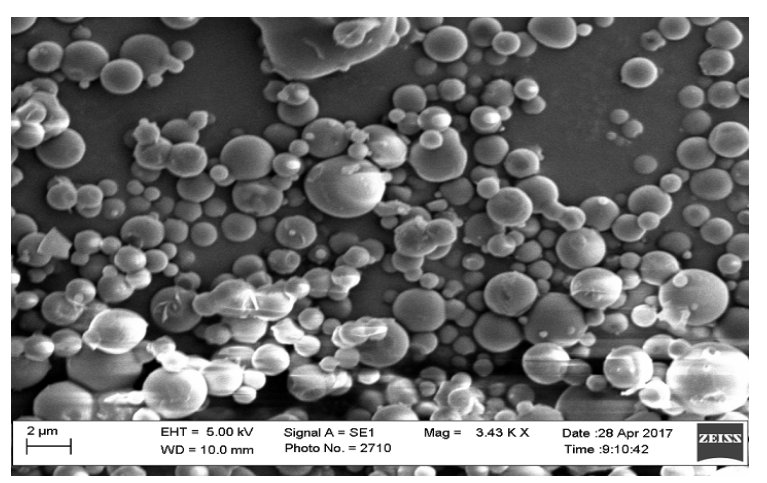

Figure 7: Scanning electron micrographs of optimized nanoparticles (F3)

\section{In vitro anti-cancer activity}

In vitro anti-cancer activity of NPs (F3), STM (free), and F3 without drug (control) were evaluated by MTT assay at different concentrations. The values of the maximum inhibition $(M I)$ and $\mathrm{IC}_{50}$ are listed in Table 3. The concentration - cell viability plots for NPs (F3), free STM suspension and control are shown in Figure 8 . The $M I$ value of free STM was $85.50 \pm$ $0.65 \%$ at maximum concentration $(20 \mu \mathrm{M})$. However, the optimized NPs (F3) showed an MI of $96.96 \pm 0.35 \%$ at the same concentration of STM $(20 \mu \mathrm{M})$, which was significantly higher, when compared to the free STM $(p<0.05)$. Thus, F3 NPs exhibited better anti-cancer efficacy than free STM.

Table 3: $\mathrm{MI}$ and $\mathrm{IC}_{50}$ data for free STM, PLGA-NPS (F3), and control after $24 \mathrm{~h}$ of therapy

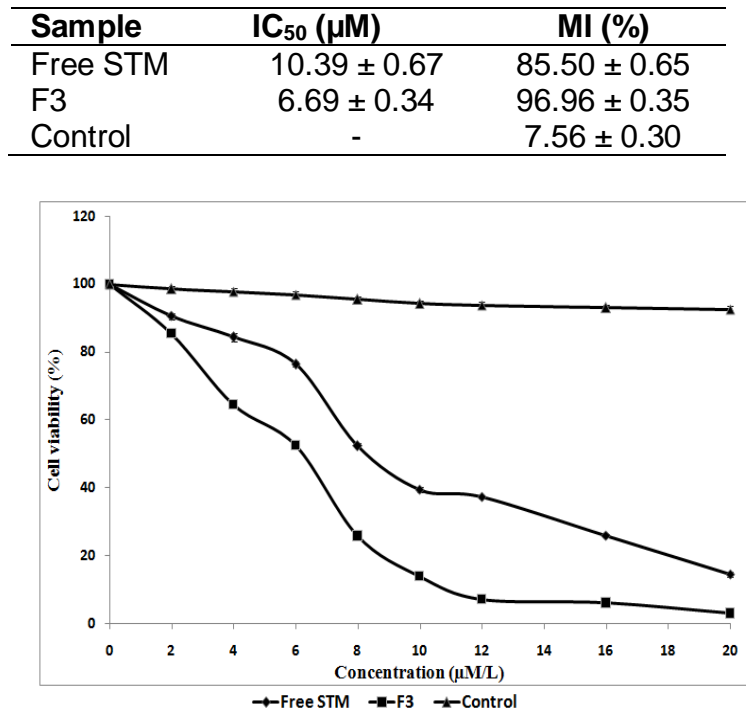

Figure 8: Effect of free STM and optimized nanoparticles (F3) on cell viability

\section{DISCUSSION}

The purpose of this study was to improve the performance with respect of bioavailability and sustainability of STM in the colon of colon cancer patients. Recently, improvement in the bioavailability of STM by SNEDDs was reported [21]. The side-effects of drugs and high degree of non-targeting limit the therapy of colon cancer. The PLGA polymer NPs could be novel alternatives for overcoming these problems by enabling delivery of drugs to the target site. In this study, three different STM-loaded PLGA-NPs (F1-F3) were developed by the nanoprecipitation method and optimized. It can be seen from the results that size of STM-loaded PLGA-NPs decreased significantly with increase in the amount of PLGA polymer used in the formulation. The lowest particle size was observed in F3 among all NPs (F1-F3), which could be due to the minimum concentration of the polymer present in F3 NPs. 
Increasing PLGA polymer concentration in $\mathrm{F} 1$ (50 mg), F2 (100 mg), and F3 (150 mg) had positive effects both on entrapment efficiency and drug loading. A slow/sustained release of the drugs into the buffer solution could be observed over $48 \mathrm{~h}$ of the dissolution study.

The slow release of the STM was due to the strong entrapment of drug inside the PLGA polymer. The DSC thermogram of the NPs and the peak of STM almost vanished at $208{ }^{\circ} \mathrm{C}$. These results clearly revealed that STM were completely entrapped in the PLGA polymer.

The FTIR spectra of NPs exhibited low intensity peaks in comparison to pure STM drug. This also confirmed the entrapment of STM inside the polymer. The amorphous form of STM drug was confirmed by the XRD pattern study. These spectral characteristics supports the data generated in the entrapment efficiency and in vitro release studies.

It could be seen from the SEM image that the optimized NPs were small and spherical in shape. The in vitro anti-cancer data indicated the dominance of developed PLGA NPs when compared with the free STM. The control PLGANPs (F3, without drug) did not suppress cell growth, which revealed that the developed STMloaded PLGA-NPs were non-toxic. The $I_{50}$ value of F3 was significantly lower than that of the free drug. The in vitro anti-cancer activity against HT-29 colorectal cells indicated that the developed STM-loaded PLGA-NPs (F3) could be administered orally for colon cancer therapy.

\section{CONCLUSION}

The outcome of this study reveal that sunitinib malate can be efficiently incorporated in PLGA polymeric nanoparticles to achieve sustained drug release. The optimized sunitinib malateloaded PLGA nanoparticles exhibit higher cytotoxicity against HT-29 cells lines than the free drug. These nanoparticles possess the potential required for efficient carriage and delivery of anticancer drugs for the treatment of colon cancer.

\section{DECLARATIONS}

\section{Acknowledgement}

This study was financed by Deanship of Scientific Research, Prince Sattam Bin Abdulaziz University, Alkharj, Saudi Arabia (Project no.5680H/03/2016).

\section{Conflict of interest}

No conflict of interest is associated with this manuscript.

\section{Contribution of authors}

We declare that this work was done by the authors named in this article, and all liabilities relating to the contents of this manuscript will be borne by the authors.

\section{REFERENCES}

1. Yassin AB, Anwer MK, Mowafy HA, El-Bagory IM, Bayomi MA and Alsarra IA. Optimization of 5-flurouracil solid-lipid nanoparticles: a preliminary study to treat colon cancer. Int J Med Sci 2010; 7: 398-408.

2. Siegel RL, Miller KD, Jemal A. Cancer statistics, 2017. CA Cancer J Clin 2017; 67: 7-30.

3. Hanahan $D$, Weinberg RA. Hallmarks of cancer: the next generation. Cell 2011; 144: 646-674.

4. Vogelstein B, Kinzler KW. Cancer genes and the pathways they control. Nat Med2004; 10: 789-799.

5. Kwon HJ, Kim Y, Sugihara Y, Baldetorp B, Welinder C, Watanabe K, Nishimura T, Malm J, Torok S, Dome B, Vegvari A, Gustavsson L, Fehniger TE, Marko-Varga G. Drug compound characterization by mass spectrometry imaging in cancer tissue. Arch Pharm Res 2015; 38 : 1718-1728.

6. Dong M, Phan AT, Yao JC. New strategies for advanced endocrine tumors in the era of targeted therapy. Clin Cancer Res 2012; 18: 1830-1836.

7. DuBois SG, Shusterman S, Reid JM, Ingle AM, Ahern $\mathrm{CH}$, Baruchel S, Glade-Bender J, Ivy P, Adamson PC, Blaney SM. Tolerability and pharmacokinetic profile of a sunitinib powder formulation in pediatric patients with refractory solid tumors: a children's oncology group study. Cancer Chemother Pharmacol 2012; 69: 1021 1027.

8. Wen J, Li HZ, Ji ZG, Jin J. Effects of sunitinib malate on growth of human bladder transitional cell line T24 in vitro. Chin Med Sci J 2015; 30: 51-5.

9. Mendel DB, Laird AD, Xin X, Louie SG, Christensen JG, Li G, Schreck RE, Abrams TJ, Ngai TJ, Lee LB, Murray LJ, Carver J, Chan E, Moss KJ, Haznedar JO, Sukbuntherng J, Blake RA, Sun L, Tang C, Miller T, Shirazian S, McMahon G, Cherrington JM. In vivo antitumor activity of SU11248, a novel tyrosine kinase inhibitor targeting vascular endothelial growth factor and platelet-derived growth factor receptors: determination of a pharmacokinetic/pharmacodynamic relationship. Clin Cancer Res 2003; 9: 327-337.

10. Talukder R, Fassihi R. Gastroretentive delivery systems: hollow beads. Drug Dev Ind Pharm 2004; 30: 405-412.

11. Zheng $X$, Zhang $Y$, Zhang L, Xu W, Ma W, Sun R, Zeng $H$. Synergistic inhibition of sunitinib and ethaselen 
against human colorectal cancer cells proliferation. Biomed Pharmacother 2016; 83: 212-220.

12. Anwer MK, Al-Mansoor MA, Jamil S, Al-Shdefat R, Ansari $M N$, Shakeel F. Development and evaluation of PLGA polymer based nanoparticles of quercetin. Int $J$ Biol Macromol 2016; 92: 213-219.

13. Anwer MK, Jamil S, Ansari MJ, lqbal M, Imam F, Shakeel $F$. Development and evaluation of olmesartanmedoxomil loaded PLGA nanoparticles. Mat Res Innovation 2016; 20: 193-197.

14. Gabrilovich DI, Nagaraj S. Myeloid-derived suppressor cells as regulators of the immune system. Nat Rev Immunol 2009; 9: 162-174.

15. Saber MM, Bahrainian S, Dinarvand $R$, Atyabi $F$. Targeted drug delivery of Sunitinib Malate to tumor blood vessels by cRGD-chiotosan-gold nanoparticles. Int J Pharm 2017; 517: 269-278.

16. Shakeel $F$, lqbal $M$, Ezzeldin $E$. Bioavailability enhancement and pharmacokinetic profile of an anticancer drug ibrutinib by self-nanoemulsifying drug delivery system. J Pharm Pharmacol 2016; 68: 772-780.

17. Shakeel F, Haq N, Al-Dhfyan A, Alanazi FK, Alsarra IA. Double w/o/w nanoemulsion of 5 -fluorouracil for selfnanoemulsifying drug delivery system. J Mol Liq 2014; 200: 183-190.

18. Shakeel F, Haq N, Raish M, Siddiqui NA, Alanazi FK, Alsarra IA. Antioxidant and cytotoxic effects of vanillin via eucalyptus oil containing self-nanoemulsifying drug delivery system. J Mol Liq 2016; 218: 233-239.

19. Lovro LS. Crystal form of Sunitinib malate. United States Patent. Patent no.: US 8,703,967B2, 2014.

20. Konduri SKM, Satya BRAK, Chowdary NV. Polymorphic form of sunitinib base. United States Patent no. US 8,466,190 B2, 2013.

21. Alshahrani SM, Alshetaili AS, Alalaiwe A, Alsulays BB, Anwer MK, Al-Shdefat $R$, Imam $F$, Shakeel $F$. Anticancer Efficacy of Self-nanoemulsifying Drug Delivery System of Sunitinib Malate. AAPS PharmSciTech 2018; 19: 123-133. 